\title{
Experimental Study of HBC Fuses with Aluminum Fuse Element at Minimum Rated Breaking Current, Maximum Rated Breaking Current and Transfer Current of Fuse-Switch Combination
}

\author{
Cristian-Eugeniu SALCEANU*, Marcel NICOLA*, Daniel OCOLEANU*, Daniela IOVAN*, \\ Sorin ENACHE EN $^{\dagger}$ \\ *National Institute for Research, Development and Testing in Electrical Engineering - ICMET/Research Department, \\ Craiova, Romania, csalceanu@icmet.ro, marcel_nicola@yahoo.com, pramlmp@icmet.ro,pdaniela@icmet.ro \\ †University of Craiova/Faculty of Electrical Engineering, Craiova, Romania, senache@em.ucv.ro
}

DOI: 10.52846/AUCEE.2021.1.10

\begin{abstract}
The article presents an experimental study of high breaking capacity fuses with aluminum fusible element with and without a eutectic point, at minimum rated breaking current, preceded by experiments at maximum rated breaking current. The paper shows that in the construction with aluminum fusible element, the fuse has no problem breaking the maximum rated breaking current, but real difficulties appears when it comes to the minimum rated breaking current. The experiments were made on a homogeneous series 6-20 A, with a focus on the $36 \mathrm{kV}, 25 \mathrm{kA}, 16 \mathrm{~A}$ fuse. The fuses suffered multiple construction changes and tests with and without a eutectic point. After several tests was found an acceptable constructive solution was, but the obtained value for the minimum rated breaking current is not a commercially attractive value. It was also tested the capacity of the fuse to transfer the breaking duty to a load break switch.
\end{abstract}

Cuvinte cheie: siguranțe cu mare putere de rupere, current de rupere, fuzibil, arc intern, serie omogenă.

Keywords: high breaking capacity, breaking current, fuse, internal arc, homogeneous series.

\section{INTRODUCTION}

Generally considered to be an elementary protection device, fuses are used to prevent disturbances caused by power currents in electrical circuits. Generally, an electrical fuse is an electrical conductor that melts under the action of power currents, cutting-out the electric current of the protected circuit. This article presents experiments performed on fuses belonging to the current-limiting fuses category. The fusible element of these high-breaking capacity fuses (HBC fuses) doesn't use silver, but $99 \%$ nickel-plated aluminum. The last set of experiments were conducted on fuses with fusible elements made of $99 \%$ nickel-plated aluminum, with a silver eutectic point. The paper shows that the HBC fuse is able to break the maximum rated breaking current, but difficulties appear at the minimum rated breaking current. Without the application of a eutectic point, an acceptable current cannot be broken. For the initial study of the phenomenon, a large number of reference fuses were made, considering previous research [1-3], each consisting simply in a length of silver fusible element housed in a ceramic tube that was filled with silica quartz and sealed at the ends. Silica quartz is the most frequently used filler material and its role has been comprehensively investigated. Granules of approximately equal size were used to fill the fuse cartridges. The inner and outer caps were made from aluminum and plated with tin. The end cap assembly sealed the fuse cartridge efficiently in order to prevent ingress of moisture and aid satisfactory operation of the fuse during short circuit and low over current fault conditions. The shape of the cartridge was tubular, this choice has an effect on the minimum fusing current and the mechanical strength of the fuse. The cartridges were checked to be sure they have good electrical insulating properties in addition to good thermal conducting properties. They were also nonporous and capable of withstanding significant thermal and mechanical shocks. Each component of the fuse assembly influences the overall performance of the high breaking capacity fuse. The properties of each component are carefully chosen to collectively control fuse operation for a particular application and can be subdivided and analyzed under the classifications of material, physical, objective and transient properties. Due to the numerous applications of fuses, their physical attributes such as size, shape and methods of constructions vary widely and are referred to as physical properties. The overall fuseoperating characteristic is derived from the individual component characteristics. Consequently, the operating response with respect to the time of a component may be referred to as its objective or transient properties [9]. All the samples were identical, only that a group contained a plain simple fusible and the other group had a globule of solder on the center of the fusible element.

Over time research has displayed in obtained current/operating time curves [4-5], that the minimum fusing current for the fuses with the solder globules was only about 60 per cent of that of the plain fuses. It turned out that the temperature rise necessary to melt the fusible with silver globule was only about $345^{\circ} \mathrm{C}$, that is $(0.6)^{2}$ times the melting point of silver, being assumed that the heating effect was proportional to the square of the current. Further experiments in which the current was raised in small increments and steady temperatures being allowed to develop after each increment, shown a change when the globules melted. 
The globules soon became red hot in spite of the fact that the wires adjacent to them remained unchanged in appearance. For a very short time, the globules glowed red and clearance was affected by the silver wires rupturing besides the globules. Subsequent examinations proved the brittleness of the silver wire in contact with solder, the wire broke immediately when touched.

Experiments resumed, but this time the currents were interrupted before the fusible melted. It was found that the resistances of the fusible passing through the globules increased by $100 \%$ per whereas the fusible without globule showed no measurable increase in resistance on cooling. The above researches were made by Metcalf; therefore, our research has focused on the rated minimum breaking current $\mathrm{I}_{3}$, a limit value that cannot be exceeded in order to ensure that a high breaking capacity fuse will trip an electrical circuit.

In the event of an MV (medium voltage) short-circuit, the simple action of a high breaking capacity fuse blowing will not cut-out the current. For values of current less than the minimum rated breaking current, the fuse blows, but cannot break the current: the arc remains present until the current is cut by external intervention. Therefore, under no circumstances should a fuse assembly be used in the zone of $I_{N}$ and $I_{3}$ [6-8]. The values of $I_{3}$ are generally between 2 and $8 \mathrm{I}_{\mathrm{N}}[9-15]$.

The presented article is based on [16]. The rest of the paper is organized as follows: Section II presents the construction of the experimental device (fuse) with versions for the homogeneous series 6-20 A, Section III presents the experiments made at the maximum breaking current, while Section IV presents the experiments made at the minimum breaking current. Conclusions are the final section.

\section{EXPerimental Device AND Test Conditions}

\section{A. Experimental fuse}

The experimental fuse presented in Fig. 1 was designed to reproduce the phenomena occurring in high breaking capacity (HBC) industrial fuses. The fusible element is made of $99 \%$ nickel-plated aluminum, $1700 \mathrm{~mm}$ long and $0.08 \mathrm{~mm}$ thick, with various widths and design variants, presented in Fig. 2.
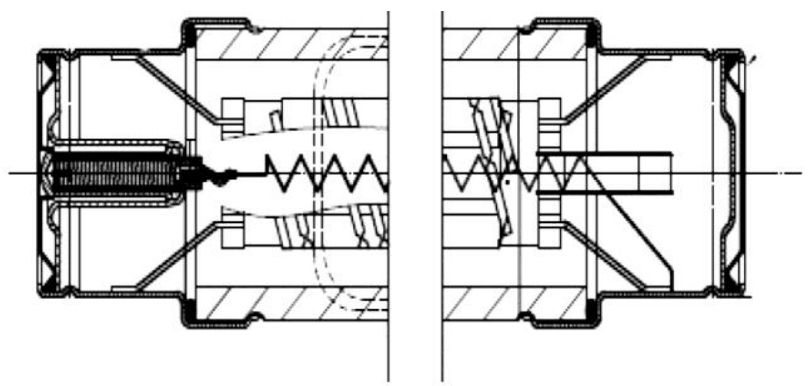

Fig. 1. Section drawing of experimental $\mathrm{HBC}$ fuse

High breaking capacity fuses may contain a single element or multiple elements connected in parallel. The elements most often have several areas of varying width referred to as "constrictions or notches". A single element may have parallel notches or "bridges". The objectives of the notches are to create areas of maximum current densi- ty and thus induce melting and subsequently arcing initially within the center location of the notch [9].

The ceramic envelope was filled with silica quartz $\left(98 \% \mathrm{SiO}_{2}\right.$ and $2 \%$ impurities $\mathrm{Na}_{2} \mathrm{O}, \mathrm{K}_{2} \mathrm{O}, \mathrm{CaO}$ ) with a grit size of less than $300 \mu \mathrm{m}$. Particular attention was paid to sand granulation, drying and filling process, because the physical processes occurring during fuse operation are closely related to the morphometric properties of sand which influence temperature and electron density [9-13].

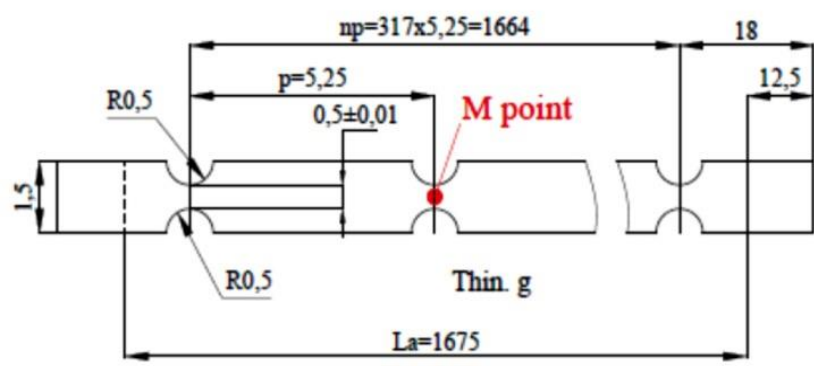

Fig. 2. Draft of the fuse element

Fig. 2 shows the variants of the design of the fusible element made for the experiments. Generally, the geometry of the fusible element is variable and may consist of wires or ribbons. HBC fuses may have a single or multiple fusible elements connected in parallel. In our experiments, we used a 2- parallel wire construction with constrictions or notches. Notches create areas of maximum current density and thus induce melting and subsequently arcing, initially within the central location of the notch.

For their execution were used precision molds to meet the imposed tolerances and to ensure the execution of any necessary quantity of identical elements. Table I presents four design variants for the homogeneous series 6-20 A. The monotonic equation imposed by IEC 60282-1; chapter 6.6.4.1 can be noted. The tested fuses have the same rated voltage $\mathrm{U}_{\mathrm{r}}=36 \mathrm{kV}$, breaking current $\mathrm{I}_{1}=25 \mathrm{kA}$, and the minimum breaking currents vary between 6 and $20 \mathrm{~A}$. For experiments, fuse V03 was chosen with 2 fuse elements connected in parallel, $36 \mathrm{kV}, 20 \mathrm{~A}, 25 \mathrm{kA}$.

TABLE I. FusE ELEMENT DESIGN VARIANTS

\begin{tabular}{|c|c|c|c|c|c|c|}
\hline Vers. & $\begin{array}{c}\text { Thin g } \\
{[\mathbf{m m}]}\end{array}$ & $\mathbf{n}$ & $\begin{array}{c}\mathbf{p} \\
{[\mathbf{m m}]}\end{array}$ & $\begin{array}{c}\mathbf{R} \\
{[\mathbf{m} \mathbf{\Omega}]}\end{array}$ & $\begin{array}{c}\mathbf{I}_{\mathbf{n}} \\
{[\mathbf{A}]}\end{array}$ & $\begin{array}{c}\text { No. of } \\
\text { elements }\end{array}$ \\
\hline V01 & 0.04 & 317 & 5.25 & 884.42 & 6 & 2 \\
\hline V02 & 0.06 & 317 & 5.25 & 589.6 & 10 & 2 \\
\hline V03 & 0.1 & 317 & 5.25 & 353.76 & 16 & 2 \\
\hline V04 & 0.14 & 317 & 5.25 & 252.68 & 20 & 2 \\
\hline
\end{tabular}

Fuse designs are closely related to applications. For new designs some parameters can be derived from mathematical models but, in general, prototype fuses have to be manufactured to enable precise characteristics to be determined by practical testing. Rapid fuse operation and current interruption are expected with this design.

The time period from the instant of fault current to the instant of element vaporization is minimized by using materials with low specific heat capacities, low melting and low vaporization temperatures. A key feature is that the energy let through to the protected circuit during this time period is minimized. 


\section{B. Experimental circuit and operations}

Fig. 3 presents the circuit used for experiments. The circuit reproduces as closely as possible the most severe conditions encountered during operation. The represented $\mathrm{G}$ source is a 2500 MVA synchronous generator capable of supplying the current passing through the fuse under test, 2 step-up 80 MVA transformers (TF), with a magnetic circuit specially designed to reduce the capacitances, both on the primary and on the secondary. $\mathrm{Z} 1$ reactor whose proportion in the circuit calculation is of $15 \%$ and it is not susceptible to saturation, is inserted on the supply side. The reactance of the circuit, which may be the reactance of the transformer or the reactance of the transformer-reactance assembly must be shunted with a resistance $R_{p}$ of a value sensibly equal to 40 times the reactance value. However, if this reactance value does not lead to at least critical damping, it must be reduced until critical damping is obtained. Critical damping is obtained when:

$$
R=\frac{1}{2} \frac{f_{0}}{f_{N}} X
$$

where: $f_{0}$ - is the inherent frequency of the circuit with no additional damping; $f_{N}$ - is the power frequency; $X$ - is the reactance of the circuit under power frequency.

MB1, MB2 and MM1 are high-precision switching pieces of equipment ensuring the desired connection, automatically programmed connection or, in case of failure, disconnection.

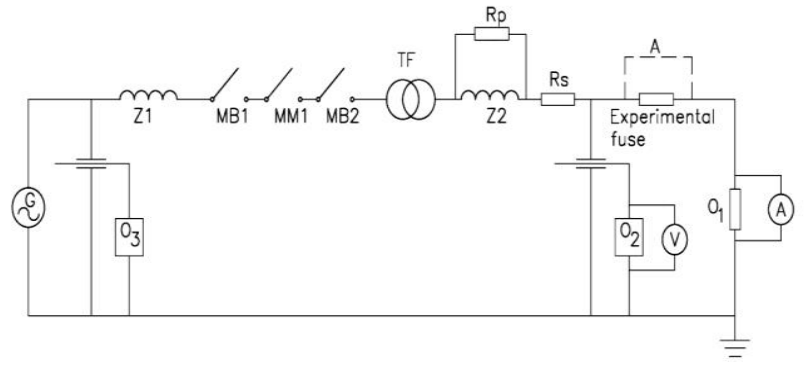

Fig. 3. The circuit used for experiments

The load side consists of resistive elements $\left(\mathrm{R}_{\mathrm{s}}\right)$ and inductive elements $\left(Z_{2}\right)$ for the adjustment of the power factor. The circuit allows a resistive load with values up to $189 \Omega$, and the inductive load consists of reactors with values between 5 and $2800 \mathrm{mH}$ which cannot be saturated. A power factor between 0.1 and 0.9 can be obtained by adjusting the values of the resistors and reactors. The over-voltage protection has been chosen so that no ignition should occur during normal fuse operation. Each operation was performed with a phase angle of the electrical fault $\varphi$ controlled and set by the operator and was achieved by using a high-precision sequential programmer that controls each switching device in the circuit; it is necessary to operate MM1 - Fig. 3, in order to ensure the phase angle of the current.

\section{Calibration of the circuit}

To check the feasibility of the testing parameters, the fuse was replaced by a dummy (copper rod) that was inserted in the fuse holder. The prospective value of the phase angle of the electrical fault $\varphi$ was obtained by measuring the phase angle between the test voltage and the prospective current, corresponding to the fault current. The prospective value of the power factor is obtained from the equation:

$$
\cos \phi=\frac{R}{\sqrt{R^{2}+L^{2} \omega^{2}}}
$$

Where $\mathrm{R}$ and $\mathrm{L}$ are the resistive and inductive components of the circuit load, and $\omega$ is the angular frequency at $50 \mathrm{~Hz}$.

\section{VALIDATION OF THE EXPERIMENTAL FusES AT THE MAXIMUM RATED BREAKING CURRENT}

$\mathrm{I}_{1}$, or the maximum breaking capacity is the maximum prospective fault current that the fuse is capable to break. Therefore, it's essential to ensure that the line short-circuit current is at least equal to the current $I_{1}$ of the fuse. In reallife situations, in the event of a short-circuit current, the link blows within several milliseconds. A peak arc voltage immediately occurs and because it is higher and opposes the generator voltage, it reduces the current value. The fuse acts as a variable resistance is almost equal to zero when the fusible blow and then increases until it reaches the current zero point while modifying the value of the current and the lag between this value and the generator voltage [14].

The experiments were carried out for the following parameters: $0.87 \times$ rated voltage $(36 \mathrm{kV})$ with $+5 \%$ tolerance, power factor between 0.07 and 0.15 at the prospective current (r.m.s. value of the periodic component) of $25 \mathrm{kA}$. Making angle of short-circuit current is from $0^{\circ}$ to $20^{\circ}$ after the voltage crosses zero. The initiation of the arc after voltage crosses zero was performed for a test with an angle between $40^{\circ}$ and $65^{\circ}$, and for two tests the angle was between $65^{\circ}$ and $90^{\circ}$. The voltage was maintained after breaking for at least 15 seconds.

During the operation, a wide variety of fuse stresses can occur and these experiments were aimed at reproducing the strictest requirements, especially in terms of the energy of the arc.

The circuit in Fig. 3 was used, with no load, zero value of $R_{p}, Z_{z}$ and $R_{s}$. The value of the reactance $Z_{1}$ was $<100$ $\mathrm{m} \Omega$. To adjust the transient recovery voltage, connected capacitors were inserted into the circuit to obtain $0.8 \mu \mathrm{F}$ and a resistance of $40 \Omega$.

After modelling the circuit to obtain the parameters of the transient recovery voltage, the graphic record in Fig. 4 was obtained.

It has been taken into account the fact that the current limiting fuses are not sensitive to the characteristics of the TRV (transient recovery voltage) unless a very high arc voltage is reached immediately after arc initiation, the circuit characteristics and the time of arc initiation between $65^{\circ}$ and $90^{\circ}$ being intended to simulate the most severe situation encountered in operation. During the tests, within a time interval less than or equal to $2 \mathrm{x} \mathrm{t}_{3}$ after arc initiation, the arc voltage did not reach the highest peak value, so the tests were considered adequate.

Fig. 5 shows the waveform of the current during calibration, with the overlapped waveform of the maximum rated breaking current. 


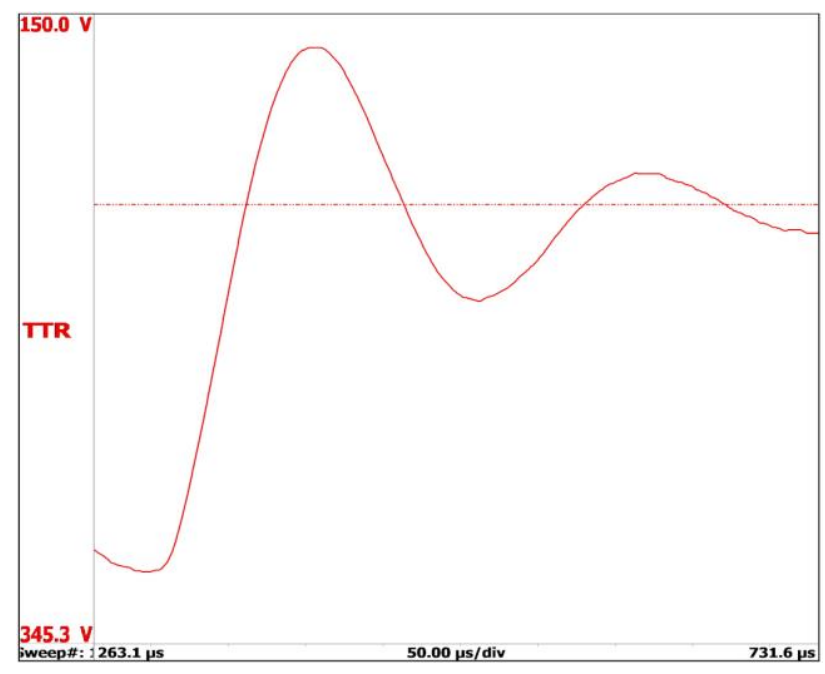

Fig. 4. Prospective transient recovery voltage with two parameters envelope, which corresponds to the imposed parameters (rate of rise $\left.\mathrm{Uc} / \mathrm{t}_{3}=0.59 \mathrm{kV} / \mu \mathrm{s}\right)$

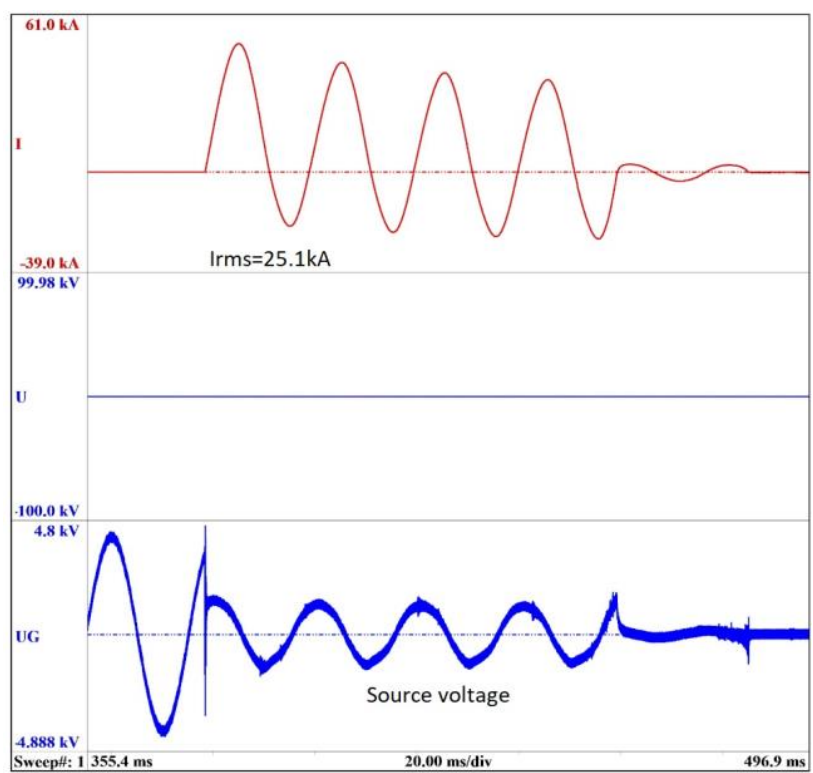

Fig. 5. Graphic record of the prospective current during calibration

In Fig. 5 the $\mathrm{U}_{\mathrm{G}}$ voltage represents the source voltage before the step-up transformers with a value of $4.41 \mathrm{kV}$. The U voltage with zero value during calibration measured with $\mathrm{O}_{2}$ voltage divider as presented in Fig. 3 .

Three fuses were tested at various phase angles of the current, and Fig. 6 presents the waveforms obtained for a 16 A fuse with a resistance of $269 \mathrm{~m} \Omega$. The values obtained for this high breaking capacity fuse are: applied voltage $32.7 \mathrm{kV}$; phase angles of the current: $77.9^{\circ} \mathrm{el}$; phase angles of the arc: $80.9^{\circ} \mathrm{el}$; limited current: $2.1 \mathrm{kA}$; recovery voltage: $32.5 \mathrm{kV}$; total energy - Joule integral: $1.6 \mathrm{kA}^{2} \mathrm{~s}$.

For $I^{2} t$ high-precision calculation under the curve in Fig. 6, the following formula was used:

$$
I^{2} t=\left\lfloor\left(\sum_{n=n_{l}}^{n_{2}} y^{2}(n)\right)-\frac{y^{2}\left(n_{1}\right)+y^{2}\left(n_{2}\right)}{2}\right\rfloor \cdot \Delta x
$$

In equation (3), $\mathrm{n}_{1}=$ first sample, $\mathrm{n}_{2}=$ last sample, and $\Delta x=$ difference between two samples, $y(n)$ represents the value of $y$ function in each $n$ sample. The numerical integration is performed by assuming the linear interpolation of the squared curve between the samples.

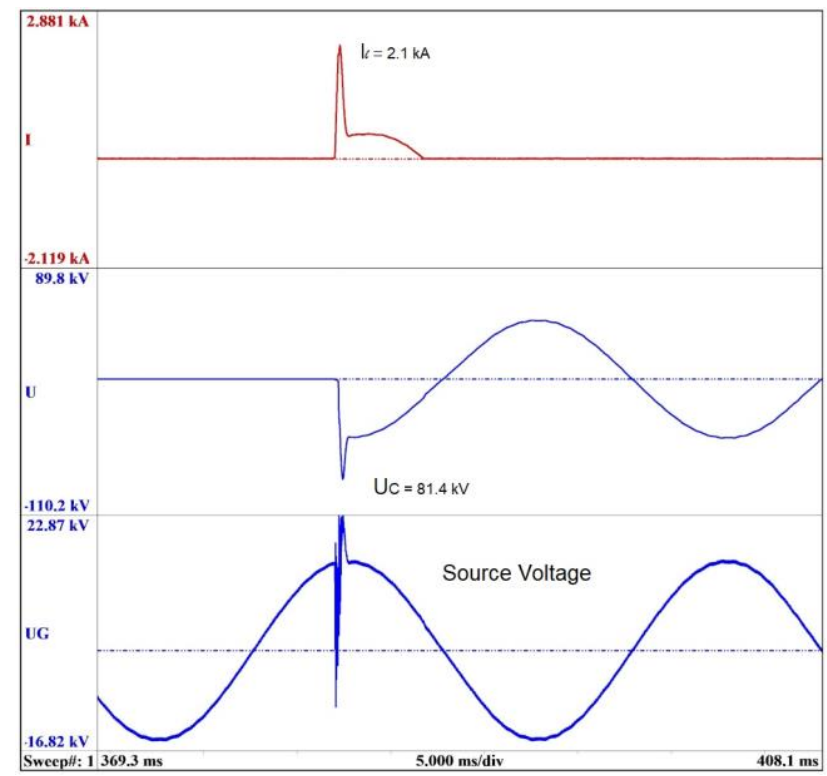

Fig. 6. Graphic record of the maximum rated breaking current

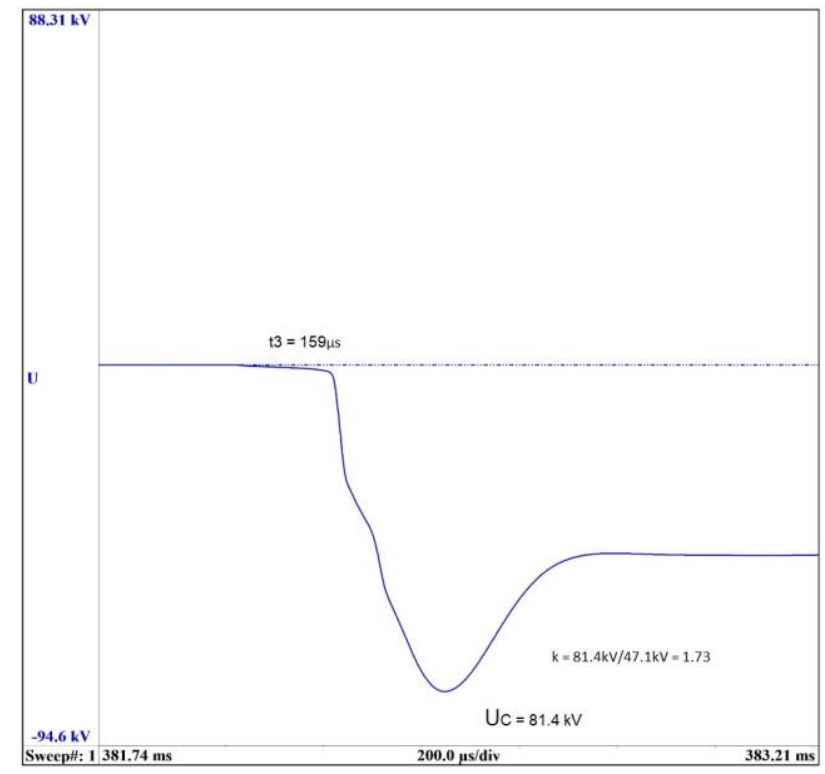

Fig. 7. Graphic record of the transient recovery voltage

Fig. 7 shows the detail of the TRV in Fig. 6. The value of the peak of voltage $U_{c}=81.4 \mathrm{kV}$, compared to the prospective value of $62 \mathrm{kV}$ and $\mathrm{t}_{3}$ (rate of rise) of $150 \mu \mathrm{s}$. The hot particles resulting under the action of the arc in the first milliseconds after the current zero passing are still in a conductive state and this conductivity results in additional damping of the transient phenomena of the recovery voltage.

The values obtained in this experiment are higher than expected, but the fuse behaved accordingly. The value of the damping is proportional to the impedance of the circuit: 


$$
\sqrt{\frac{L}{C}}=2 \pi f_{0} L
$$

The limited current is $2.1 \mathrm{kA}$ as stated in Figure 5. The obtained peak recovery voltage $\mathrm{U}_{\mathrm{C}}$ is $81.4 \mathrm{kV}$ compared with a minimum of $63 \mathrm{kV}$ imposed by IEC 60282-1 standard. The circuit was calculated for a value of $62 \mathrm{kV}$.

The transient phenomena at high inherent frequency $\mathrm{f}_{0}$ are much more damped than those at a lower inherent frequency. These transient low-frequency phenomena are maintained for a longer time and, because they overlap the recovery voltage at power frequency, subject the melted element to additional voltage stress.

According to the results obtained above, it is concluded that the fuse is capable of breaking the current under the most severe operating conditions.

\section{EXPERIMENTS AT THE MinimUM RATED BREAKING CURRENT}

The experimental tests at rated breaking current were performed at the rated fuse voltage with a margin of $+5 \%$ and a power factor between 0.4 and 0.6 [15]. The breaking current shall be the r.m.s. value of the periodic component of the current, measured at the time of arc initiation during the breaking test. The experiments were performed on high breaking capacity fuses with the highest rated current because this test is not required in the standards if the I3/s ratio of any fuse in the homogeneous series is smaller than that of the tested fuse.

For the tests presented below was used the circuit in Figure 3. Its parameters were calculated to obtain a prospective current between 100 and $200 \mathrm{~A}$. The reactance used for the supply side is $\mathrm{Z} 1=1200 \mathrm{~m} \Omega$ and $Z 2=330 \mathrm{mH}$ series connected with $\mathrm{Rs}=60 \Omega$ are used on the load side. For the presented graphic record, in the parameters of the circuit calculation $\cos \varphi=0.5$ was used, while the values at the source are $9 \mathrm{kV}$ and $50 \mathrm{~A}$, and the transformation ratio used is $\mathrm{k}=4.28$.

The fuse has to be capable of breaking any current between the minimum value of the breaking current and the maximum short-circuit current. One of the qualities of fuses, commercial appealing, is that the value of the minimum breaking current is close to the value of the rated current.

Usually, the minimum breaking current is between 4 and 8 rated current, and this value must be validated by tests. There is no maximum value of the maximum breaking current imposed in the standards however, a small value is appealing and can be a criterion in the specification. At the beginning of the experiments, we started from a current value resulting from the calculation: $6 \mathrm{x}$ IN, while the calibration current is $100 \mathrm{~A}$. The obtained graphic record is presented in Fig. 8.

In any switching device after the arc occurrence, for the arc extinguishing operation to be successful, is necessary that the curve of the dielectric strength does not intersect with the curve of the supply voltage. Any intersection of the two curves involves the re-ignition of the arc and often the increasing of its duration beyond the limits withstood by the fuse leads to fuse breaking and blowing out.

In Fig. 8 it can be noted that the arc occurs after $3100 \mathrm{~ms}$ from the initiation of the current, the arc voltage increases with the tendency to become the power frequency recovery voltage, but the dielectric strength of the fuse does not increase fast enough, so the arc re-ignites countless times, causing high arc energy and thus the blow-out of the fuse.

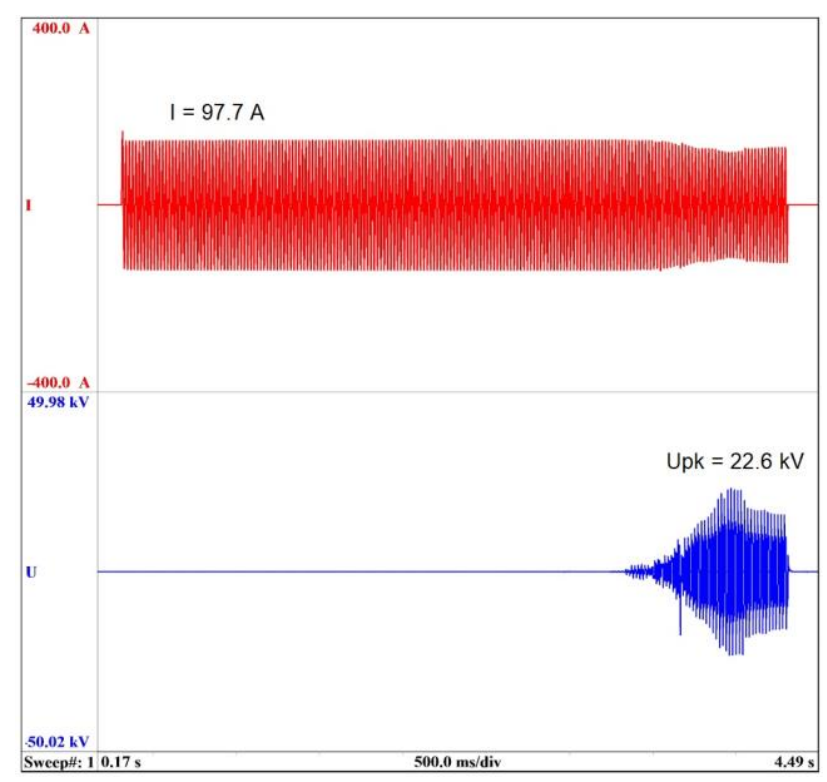

Fig. 8. Graphic record of the test $36 \mathrm{kV}, 100 \mathrm{~A}$

An important part is also played by the pre-arcing time (elongation), for its entire duration the fuse is heated and the conditions for arc extinguishing change, the longer it lasts, the more difficult the breaking becomes. By analyzing the scraps of the fuse, it was concluded that one of the fusible wires of the fuse broke (according to the graphic record at $3200 \mathrm{~ms}$ ), but this was not enough for the fuse to break the current.

The next step consisted in modifying the test circuit to ensure a prospective current of $130 \mathrm{~A}$, and the resulting graphic record is shown in Fig. 9. The pre-arcing duration decreased to $1900 \mathrm{~ms}$, but the internal processes in the fuse body were repeated, and the fuse blew out.

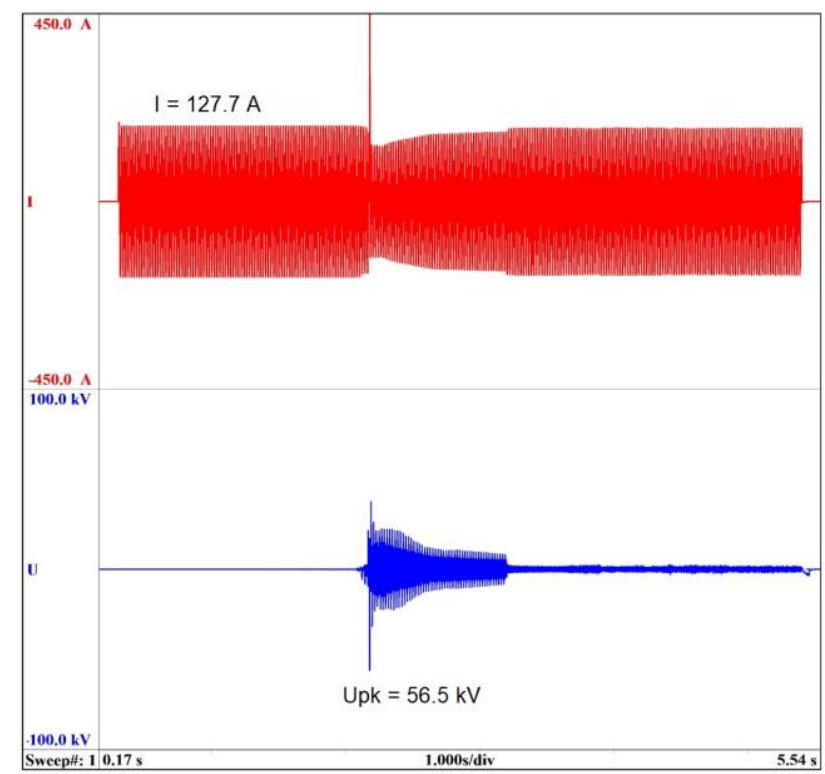

Fig. 9. Graphic record of the test $36 \mathrm{kV}, 130 \mathrm{~A}$ 
A conclusion for the exact cause could not be taken, many phenomena are associated with the disintegration of electrical conductors. Consequently, the disintegration of electrical conductors and significantly the disintegration of fuse elements need to be categorized relative to criteria of specific phenomena to clarify the arcing behavior.

There are three categories associated with fuse element explosions: slow, fast and super-fast [9].

After analyzing the fuse element disintegration, based on the magnitude of current density, in the range $10^{1} \sim 10^{4} \mathrm{~A} / \mathrm{mm}^{2}$, we can categorize it as fast. Super-fast explosions of electrical conductors in practice are not feasible due to the inherent inductance of practical circuits [3]. Further, the test current was not increased, because its value had already exceeded $8 \times \mathrm{I}_{\mathrm{N}}=128 \mathrm{~A}$. The fusible element was modified, by adding a eutectic point $\mathrm{M}$ in the middle (Fig. 2).

This solution was not initially used, because the fuse becomes sensitive to temperature rise tests and to the maximum breaking current. This technique, named after AW Metcalf [5] adds a point from another alloy on the fuse element, in a sensitive spot. The eutectic temperature is lower than the melting temperature of the fuse element, which leads to a cut-off at lower currents.

Tests were performed starting with $2 \times \mathrm{I}_{\mathrm{N}}=32 \mathrm{~A}$, and, although the times obtained were shorter than those preceding the addition of the eutectic point $\mathrm{M}$, the tested fuses failed to break the applied current.

The first successful test was obtained at a prospective current of $150 \mathrm{~A}$, and is shown in Fig. 10.

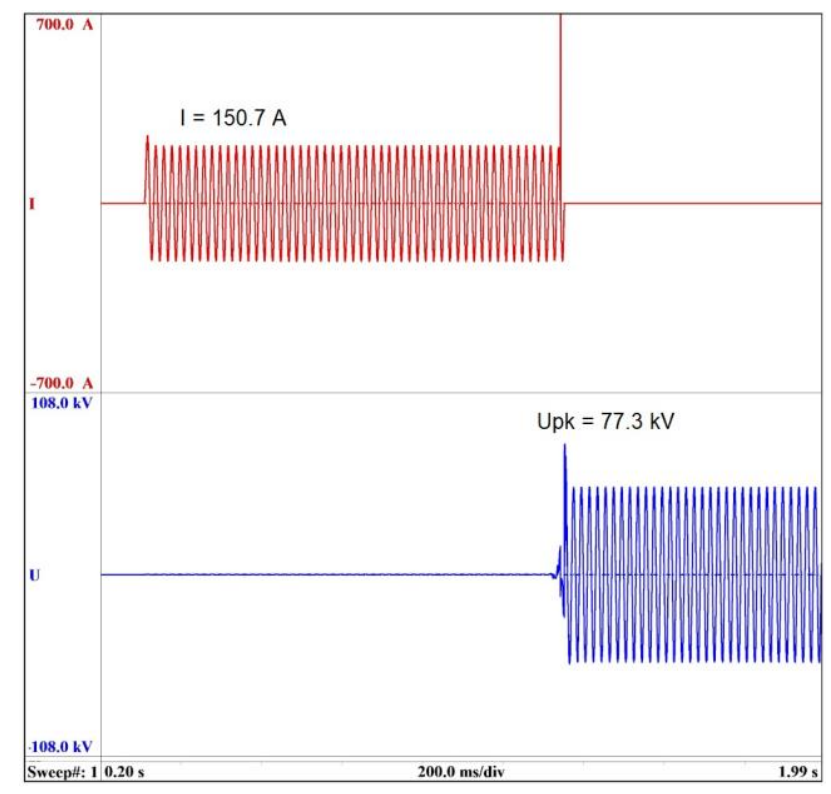

Fig. 10. Graphic record of the test $36 \mathrm{kV}, 150 \mathrm{~A}$

As seen in Fig. 10, after $1000 \mathrm{~ms}$ of pre-arcing, the current is successfully broken and the power frequency voltage is restored. When the arc current passes zero a surge occurs, however, due to the dielectric strength created inside, the fuse withstands this surge successfully.

The values obtained are the following: $\mathrm{I}=150.7 \mathrm{~A}$; Joule integral on pre-arcing $\mathrm{I}^{2} \mathrm{t}_{\mathrm{pa}}=23.11 \mathrm{kA}^{2} \mathrm{~s}$, Joule integral on arc period $\mathrm{I}^{2} \mathrm{t}=23.99 \mathrm{kA}^{2} \mathrm{~s}$, operating time $\mathrm{t}=1.04 \mathrm{~s}$; arcing time $\mathrm{t}_{\mathrm{to}}=0.027 \mathrm{~s}$.

\section{EXPERIMENT ON AN ASSEMBLy OF SWITCHES AND High BREAKING CAPACITY FUSES}

Fig. 11 presents a simplified circuit of an assembly of switches and HBC fuses capable of breaking at rated voltage $(36 \mathrm{kV})$ any current up to and including the rated short-circuit current. It is also capable of making but this was not verified during this experiment.

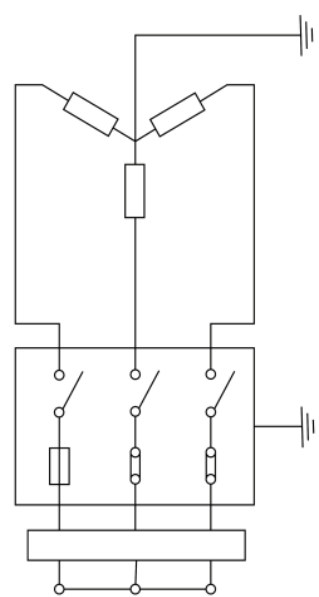

Fig. 11. Arrangement of the test circuit

The fuses are incorporated in this assembly in order to extend short-circuit breaking rating beyond that of the switch alone. The HBC fuses are fitted with strikers in order both to open automatically all three poles of the switch on the operation of a fuse and to achieve a correct operation at values of fault current above the minimum melting current, but below the minimum breaking current of the fuses. The purpose of the experiment is to check if the values obtained in previous experiments are enough for a safe operation of the load break switch in case of fault. For this, the specific mechanism of the load break switch was disabled. The load break switch could only be operated by the action of the fuse's strikers.

The earthing switches were in the open position and a $\varnothing 1 \mathrm{~mm}$ copper wire was tied across all three phases downstream the fuses to simulate a fault and to produce an internal arc. The link between the HBC fuse strikers and the switch release must be such that the switch operates satisfactorily under both three-phase and single-phase conditions at the minimum and maximum requirements of the striker, no matter of the method of striker operation.

The assembly in Fig. 12 was designed so that the combination of fuse-switch will perform satisfactorily at all values of breaking current from the rated maximum breaking current of the switch down to the minimum melting current under low over-current conditions. To prove the time coordination between the switch and fuse, the fuse initiated opening time must be shorter than the maximum arcing time the fuse can withstand, values obtained in previous experiments [16].

The experiment should have been connected in a circuit having the neutral point of the supply isolated and the neutral point of the three-phase short-circuit earthed. Given the capacity of the test site, this condition could not be done so, the supply was earthed and the three-phase short circuit was isolated, as shown in Fig. 11. 


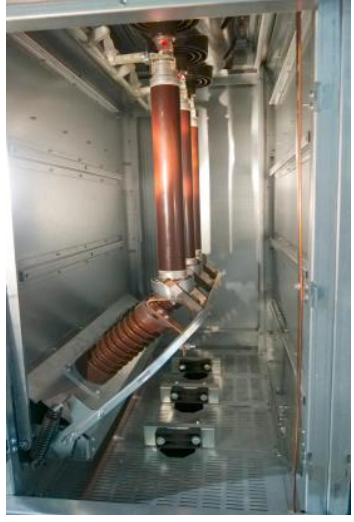

Fig. 12. Assembly of HBC fuses and in the upper part LBS

For the first test, with the circuit from Fig. 11, the high breaking capacity fuses from two poles were replaced by solid links of negligible impedance, having the same shape, dimension and mass of the high breaking capacity fuses they replace. The circuit consisted of a three-phase supply and load circuit (L-R series). The supply circuit had a power factor lower than 0,2 , the impedance of $\sim 15 \%$ of the total impedance of the circuit. The prospective TRV of the supply circuit under shorts-circuit condition was in concordance with the one used in Chapter III.

The fuse worked properly, as can be observed in Fig. 13 , the fuse managed to open the LBS. Values obtained $I_{1,2,3}=620 \mathrm{~A}$, where $I_{2}$ is the current limited by the fuse, the fuse cut the current after $16,2 \mathrm{~ms}$ and after $77,7 \mathrm{~ms}$ the LBS also break the current, which is near the no-load opening time of the LBS. The recovery voltage was the rated voltage divided by 2 . The TRV peak voltage $U_{C}=60 \mathrm{kV}$ with a rate of $U_{C} / t_{3}=0,3 \mathrm{kV} / \mu \mathrm{s}$. Next, three new fuses were inserted and short-circuit made with $\varnothing 1 \mathrm{~mm}$ copper wire downstream the fuses. The prospective applied voltage is $36 \mathrm{kV}$ with $20 \mathrm{kA}$, for $1 \mathrm{~s}$. To obtain a peak current the closing of the master maker was delayed for $2.7 \mathrm{~ms}$ (Fig. 14).

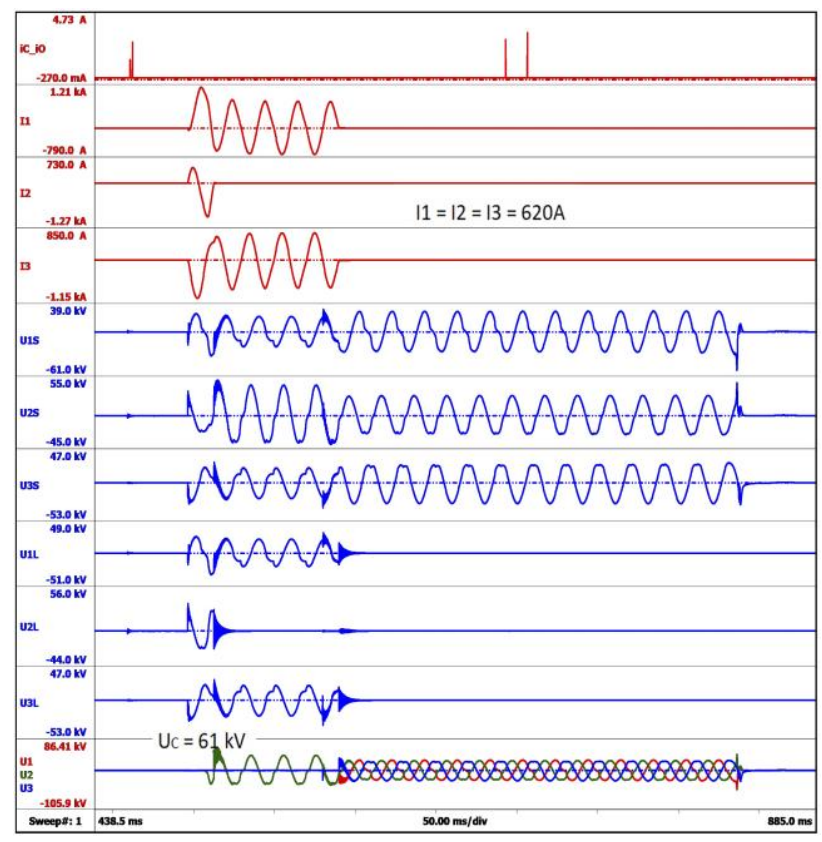

Fig. 13. Graphic record of the test with prospective values $36 \mathrm{kV}$, $630 \mathrm{~A}$

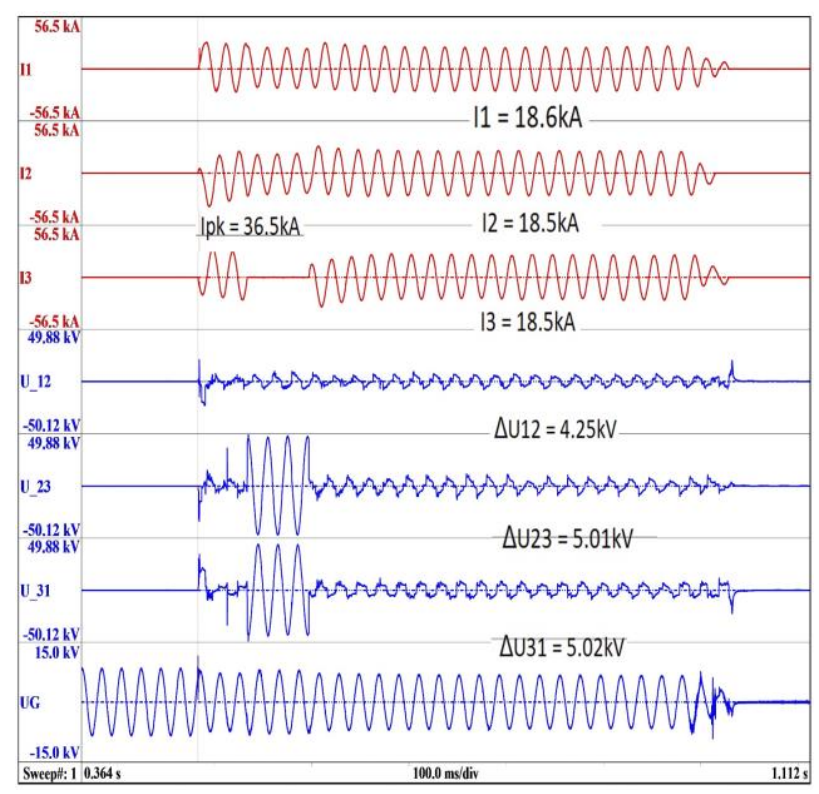

Fig. 14. Graphic record of the test with marker on the 2.7 ms delay

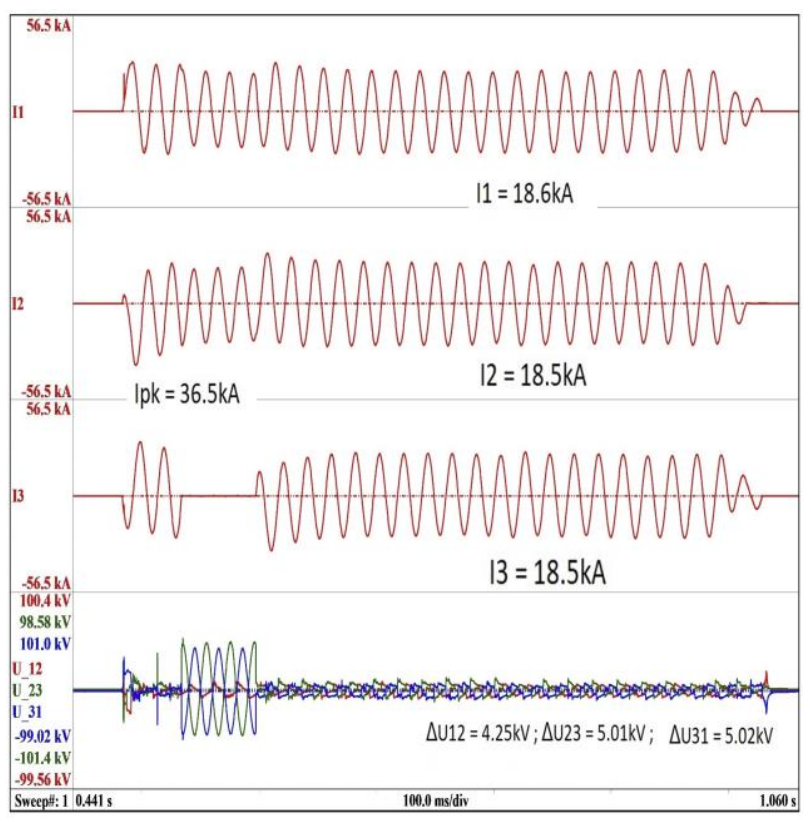

Fig. 15. Graphic record of the test $36 \mathrm{kV}, 20 \mathrm{kA}$

After $50 \mathrm{~ms}$ on $\mathrm{L}_{3}$ phase, the fuse worked but it wasn't able to break the current or to transmit the breaking operation to the LBS (Fig. 15). The result can be seen in Fig. 16. The result was not adequate. Because the assembly was destroyed during the test, it is required to be made further experiments, in order to make any conclusion for this.

Values obtained:

$\mathrm{I}_{\mathrm{pk}}=29.1 /-36.5 / 31.9 \mathrm{kA}$;

$\mathrm{I}_{\mathrm{rms}}=18.6 / 18.5 / 18.5 \mathrm{kA}$;

Connection: $2.7 \mathrm{~ms}$ after zero of the supply;

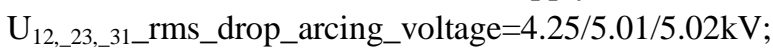

$\mathrm{U}_{-23,31}=33.6 / 31.2 \mathrm{kV}$ - line voltage measured between the phase that opened L3 and one of the remaining closed phases. 


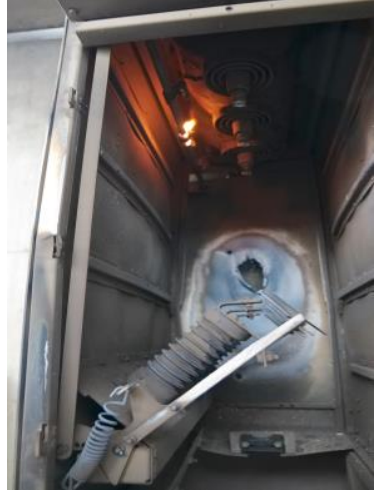

Fig. 16. Aspect of the assembly after the experiment

In summary, after analyzing the remaining of the HBC fuses, the phenomena of unduloid formation on the fusible element have been observed, which propose that the mechanism of disintegration is dependent on the instability of the liquefied cylinder [17-24] and the evolution of the cylinder into stable spheres. Cylinder instability due to electromagnetic forces is questionable since in separate cases unduloids have been observed to form due to stored thermal energy. Alternatively, it assumed uneven temperature distribution would induce disintegration, which would occur at the hottest point, usually at the center of the conductor.

\section{CONCLUSIONS}

The experiments were performed in a high-power laboratory that allowed the adjustment of the values needed to obtain the required parameters. The measurements were acquired using TRAS (Genesis optically isolated digitizer): $100 \mathrm{Ms} / \mathrm{s}$, 16-bit, 1 GB Memory Channel, 24 channels. The first experimental results were obtained for the most severe operating conditions $0.87 \mathrm{X} 36 \mathrm{kV}$ and $25 \mathrm{kA}$, at different phase angles of the current. They checked the experimental solution for the maximum rated breaking current; the experiments were performed without applying a eutectic point $\mathrm{M}$ on the fuse element. The next set of experiments was performed in order to demonstrate the capacity of the fuse to break the nominal minimum breaking current, without applying a eutectic point M. Although one or more fusible elements in the structure of the fuse broke, the fuse as a whole was not capable to break these currents. In the final experiments, fuses of the same design were used, but a eutectic point was applied to their fusible element. When a current of $9 \mathrm{xI}_{\mathrm{N}}$ was applied, the fuse broke the current after $1000 \mathrm{~ms}$ in satisfactory conditions. However, this value of the current does not make this type of fuse an actual competitor for fuses with silver fusible elements. The project includes the execution of other design types of fuse elements, to verify whether the results obtained can be improved.

\section{ACKNOWLEDGMENT}

The paper was developed with funds from the Ministry of Education and Scientific Research - Romania as part of the NUCLEU Program: PN 19380204.

Contribution of authors:

First author $-60 \%$; First coauthor $-10 \%$;

Second coauthor $-10 \%$; Third coauthor $-10 \%$

Fourth coauthor $-10 \%$
Received on August 4, 2021

Editorial Approval on November 10, 2021

\section{REFERENCES}

[1] Y. Kawase, T. Mivatake, S. Ito, "Heat analysis of a fuse for semiconductor devices protection using a 3-D finite element method," in IEEE Trans. Magn., vol. 36, no. 4, pp. 1377-1380, July 2000.

[2] D. Rochette and W. Bussiere, "Pressure evolution during HBC fuse working," in Plasma Sources Science and Technology, vol. 13, no. 2, pp. 293-302, April 2004

[3] A. Wright and P.G. Newbery, Electric Fuses 3rd Edition, Power and Energy Series 49.

[4] M. Young, The Technical Writer's Handbook. Mill Valley, CA: University Science, 1989.

[5] A. W. Metcalf, "A new fuse Phenomena", BEAMA Journal 44, p.109, 151, 1939.

[6] A. L.Wilkins, "Use of semiconductor - protection fuses on DC Drives/ Motors/Controls", UK, 1987

[7] A. Wright and P. G. Newbery, 2004 Electric Fuses (IEEE Power and Energy Series 49) 3rd ed. (London: The Institution of Electrical Engineers).

[8] O. Bouilliez and J. C. P. Quesada, "Design and use of MV currentlimiting fuses", Cahier technique no.128.

[9] Brown, Robert Ernest, "Investigation of disintegration and arcing in electric fuses", Doctoral, Sheffield Hallam University

[10] T. Reichelt, "Numerical and Analytical Solution of the Transient Adiabatic Joulean Heat Equation of Common Electrical Conductors", Diplomarbeit, Technische Universitat Ilmenau, 1997.

[11] W. Bussiere, "Influence of sand granulometry on electrical characteristics, temperature and electron density during high-voltage fuse arc,” J. Phys. D: Appl.Phys, 2001.

[12] M. Lindmayer, "3D simulation of fusing characteristics using the M-effect," The 6th international conference on Electric fuses and their applications, Instituto Elettrotecnico Nazionale Gailieo, Ferraris, Torino, Italy, 1999, pp. 13-20.

[13] T. Yorozu, M. Hirano, K. Oka, Y. Tagawa, "Electron Spectroscopy Studies on Magneto-Optical Media and Plastic Substrate Interface," in IEEE Translation Journal on Magnetics in Japan, vol. 2, no. 8, pp. 740-741, Aug. 1987.

[14] L. A. Kojovic, S. P. Hassler, H. Singh, C. W. Williams, "Currentlimiting fuses improve power quality," in IEEE/PES Transmission and Distribution Conference and Exposition. Developing New Perspectives (Cat. No.01CH37294), vol.1, pp. 281-286, April 2001.

[15] IEC 60282-1:2002 High-voltage fuses - Part 1: Current-limiting fuses

[16] C. -E. Salceanu, M. Nicola, D. Ocoleanu, D. Iovan, S. Enache, "Experimental Study of HBC Fuses with Aluminum Fuse Element at Minimum Rated Breaking Current," International Conference on Applied and Theoretical Electricity (ICATE), Craiova, Romania, 2021, pp. 1-6.

[17] Baxter, H.W., "Arcing Characteristics of Fuses with Small Over Currents (DC and AC)," The British Electrical and Allied Industries Association, Report G/T 228, 24 March 1950

[18] Aslak Ofte, Rondeel, W., "Test Procedures and Arcing Phenomena in HV Fuse Links near the Minimum Breaking Current," in Conference Proceedings, International Conference on Electrical Fuses and their Applications, Trondheim, Norway 13-15 June 1984, pp. 190-195.

[19] Mr. Edward Nairne FRS - Discoverer of the Electrical Fuse

[20] Mc. Ewan, P.M., "Prospects of Developments of Current Breaking Techniques," PTWPiS, Gdansk, 1996

[21] Carne, E.B., "A Mechanism for the Fuse Pre-Arcing Period," A.I.E.E. Transactions, Vol. 72, 2 March 1953, pp. 593-599

[22] Lipsky, T., "Why Unduloids Do Not Always Appear," Conference Proceedings, 3rd International Sumposium on Switching Arc Phenomena, Lodz, Poland. 1977, pp. 305-309

[23] Bisaria, A.K., "Appearance of Unnuloids in Exploding Wire Phenomenon," Indian Journal of Pure Applied Physics, Vol. 11, September 1973.

[24] Meyer, E., Rinderer, L., "Use of Capillary and Pinch Instability for Dendritic Crystal Growing”, Journal of Crystal Growth, Vol. 28, 1975, pp. 199-208 